\title{
STEREOSPECIFICITY OF CINNAMYL ALCOHOL DEHYDROGENASE AND SYNTHESIS OF STEREOSPECIFICALLY LABELLED CONIFERYL ALCOHOL
}

\author{
Martina Klischies, Joachim Stöckigt and Meinhart H. Zenk \\ Lehrstuhl für Pflanzenphysiologie, Ruhr-Universität Bochum, D 4630 Bochum, West Germany
}

(Received 12 December 1977)

Key Word Index - Forsythia suspensa; Oleaceae; cinnamyl alcohol oxido-reductase; cinnamyl alcohol; cinnamyl aldehydes; stereospecificity.

\begin{abstract}
Using horse liver alcohol dehydrogenase, stereospecifically tritiated $(R)$ - and $(S)-\left(\gamma-{ }^{3} \mathrm{H}\right)$-coniferyl alcohol was synthesized. Using both of these substrates it was demonstrated that cinnamyl alcohol dehydrogenase from lignifying Forsythia tissue specifically removes the pra- $R$-hydrogen atom of coniferyl alcohol in the oxidation to the aldehyde. This also means that in the reverse reaction the A-hydrogen of NADPH is transferred to the Re-site of coniferyl aldehyde.
\end{abstract}

\section{INTRODUCTION}

In recent years the biosynthesis of lignin monomers has been clarified at the enzymic level [1]. Although the reduction of ferulic acid to coniferyl alcohol, the immediate lignin precursor is well understood the stereochemistry of the reduction of coniferyl aldehyde to coniferyl alcohol has not yet been determined. This reduction is catalysed by the highly substrate specific cinnamyl alcohol dehydrogenase [2-4] found in lignifying tissue of higher plants. The principle solving the question of how substances which possess a prochiral centre of the type $\mathrm{A} \mathrm{CH}_{2} \mathrm{~B}$ can be made chiral by replacement of one or the other hydrogen atoms with a heavy hydrogen isotope has been worked out in detail [see 5]. Following this principle for the synthesis of $(R)$ and $(S)$ labelled alcohol groups using the remarkable versatility of horse liver alcohol dehydrogenase, it was possible to synthesize labelled $(R)$ and $(S)-\left(\gamma-{ }^{3} \mathrm{H}\right)-$ coniferyl alcohol. The use of these two forms of stereospecifically labelled coniferyl alcohol and the cinnamyl alcohol dehydrogenase from a plant source allowed us to determine the stereospecificity of the plant enzyme.

\section{RESULTS AND DISCUSSION}

In preliminary experiments, it could be shown that commercially available horse liver alcohol dehydrogenase will catalyze the oxidation or reduction of a wide range of cinnamyl alcohol or aldehyde substrates. Using labelled $\left[{ }^{3} \mathrm{H}\right]$-cyclohexanol as the reducing agent [5] coniferyl aldehyde as substrate and liver $\mathrm{ADH}$ as the catalyst, it was possible to synthesise the $(R)-\left(\gamma-{ }^{3} \mathrm{H}\right)$-coniferyl alcohol (see Scheme 1).

The synthesis of $(S)-\left(\gamma-{ }^{3} \mathrm{H}\right)$-coniferyl alcohol was undertaken in several steps, First coniferyl aldehyde was

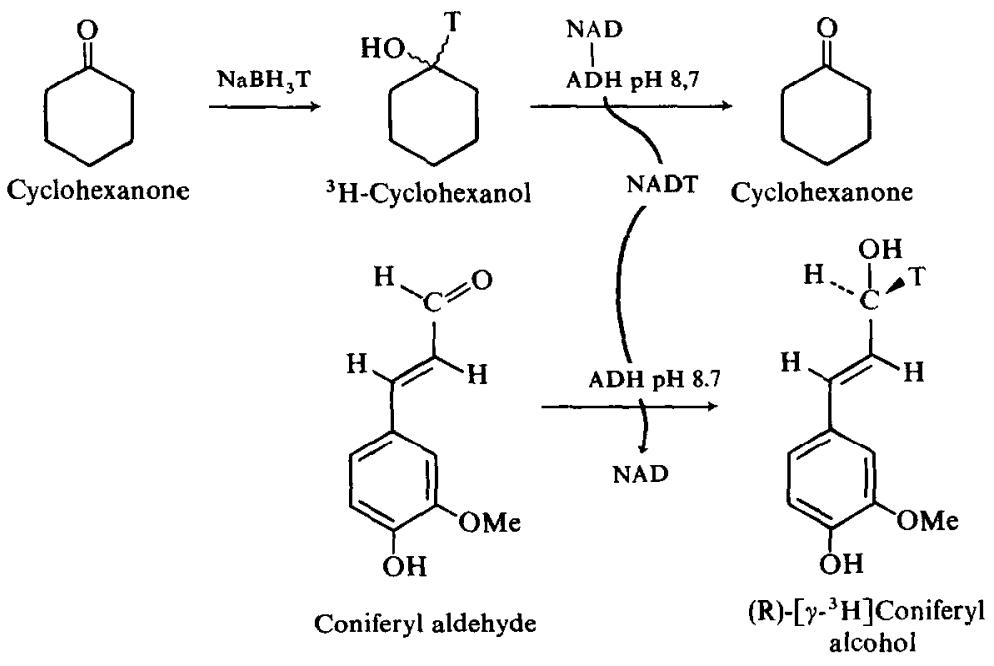

Scheme 1. Preparation of $(R)-\left(y,-{ }^{3} \mathrm{H}\right)$-coniferyl alcohol. 


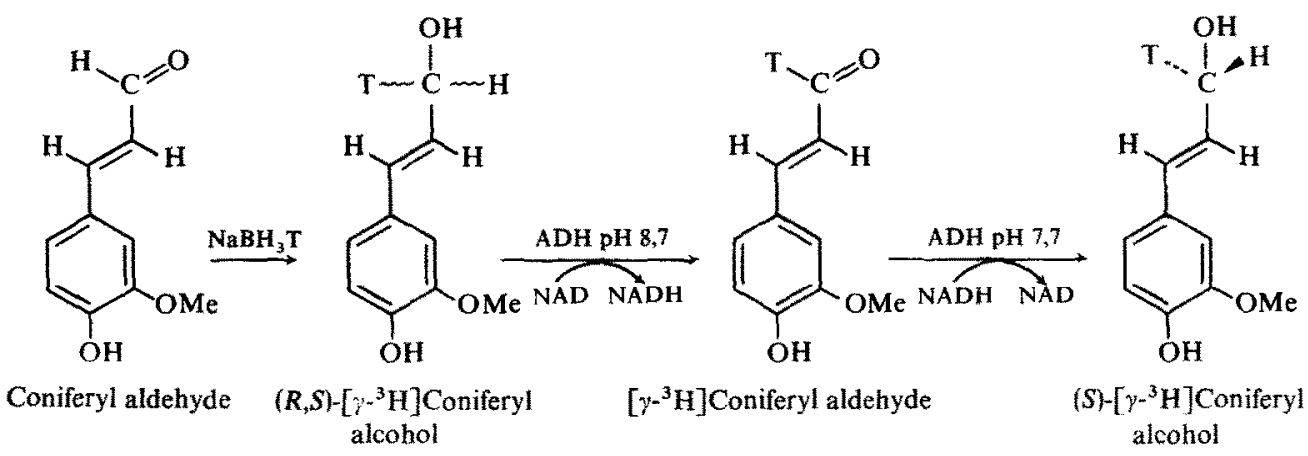

Scheme 2. Preparation of $(S)-\left(\gamma_{-}{ }^{3} \mathrm{H}\right)$-coniferyl alcohol.

reduced chemically by $\mathrm{NaBH}_{3} \mathrm{~T}$ to a racemic mixture of $(R, S)-\left(\gamma-{ }^{3} \mathrm{H}\right)$-coniferyl alcohol. Subsequently the labelled coniferyl alcohol was converted by the action of liver ADH and NAD to $\left(\gamma^{3} \mathrm{H}\right)$-coniferyl aldehyde: during this reaction the $(R)-{ }^{3} \mathrm{H}$-atom of the alcobol group was transferred onto the pyridine nucleotide. The $\left(\gamma-{ }^{3} \mathrm{H}\right)$ coniferyl aldehyde was isolated, purified and again reduced at the Re-site of the aldehyde molecule using unlabelled NADH and liver ADH. The overall radiochemical yield of the alcohol was $60.5 \%$ of that theoretically expected. The outline of these steps to $(S)-\left(\gamma-{ }^{3} \mathrm{H}\right)$ coniferyl alcohol is shown in Schcme 2.

Both $(R)$ - and $(S)-{ }^{3} \mathrm{H}$-labelled coniferyl alcohol were separately incubated with the highly substrate specific plant cinnamyl alcohol dehydrogenase and NADP as co-substrate and the reaction was allowed to proceed for two hours. The resulting coniferyl alcohol was isolated and rigorously purified. As can be clearly seen in Table 1, the specific activity of the isolated coniferyl aldehyde is the same as that of the $(S)-\left(\gamma_{-}{ }^{3} \mathrm{H}\right)$-coniferyl alcohol used as substrate in this reaction. In contrast using $(R)-\left(\gamma-{ }^{3} \mathrm{H}\right)$-coniferyl alcohol as a substrate, almost the entire radioactivity is lost and the resulting coniferyl aldehyde is radioinactive. These results also prove the high enantiomeric purities of both labelled coniferyl alcohols.

The results clearly demonstrate that during the oxidation of coniferyl alcohol to coniferyl aldehyde cataly $/ e d$

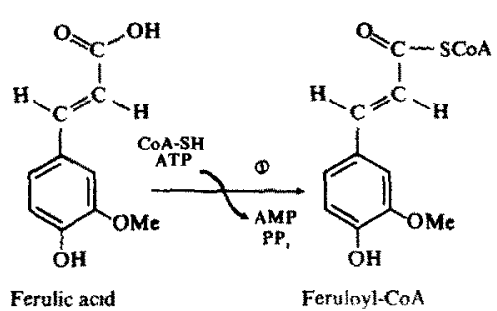

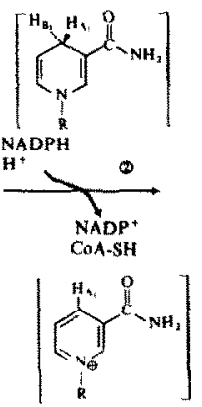<smiles>COc1ccc(/C=C/C=O)cc1OC</smiles>

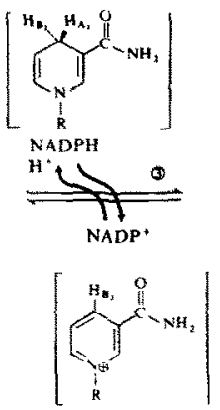

Scheme 3. Sequence for the enzymic reduction of ferulic acid to coniferyl alcohol catalysed by: (1) Hydroxycinnamoyl-CoA ligase. (2) Cinnamoyl-CoA: NADP-reductase (3) Cinnamyl-alcohol: NADP-dehydrogenase.

Table 1. Stereochemical course of cinnamyl alcohol dehydrogenase reaction

\begin{tabular}{lccccc}
\hline Substrate & $\begin{array}{c}\text { Coniferyl alcohol } \\
\mu \mathrm{mol}\end{array}$ & $\begin{array}{c}\text { Sp. act. } \\
(\mathrm{dpm} / \mu \mathrm{mol})\end{array}$ & $\begin{array}{c}\text { Coniferyl aldehyde (product) } \\
\text { Spolated } \\
(\mu \mathrm{mol})\end{array}$ & $\begin{array}{c}\text { Sp. act. } \\
(\mathrm{dpm} / \mu \mathrm{mol})\end{array}$ & $\begin{array}{c}{ }^{3} \mathrm{H} \text { Rentention } \\
(\%\end{array}$ \\
\hline $\begin{array}{l}(R)-\left(\gamma^{3} \mathrm{H}\right) \\
(S)-\left(\gamma{ }^{3} \mathrm{H}\right)\end{array}$ & 7.8 & $0.29 \times 10^{6}$ & 0.412 & $0.005 \times 10^{\circ}$ & 195 \\
\hline
\end{tabular}

The indicated amount of conferyl alcohol was incubated with NADP ( $8 \%$ short of the stoichiometrical amount), $14 \mathrm{mU}$ of cinnamyl alcohol dehydrogenase and $100 \mu \mathrm{mol}$ glycine buffer in a total vol. of $3 \mathrm{ml}$ for $2 \mathrm{hr}$ at $30^{\circ}$. 
by Forsythia derived cinnamyl alcohol dehydrogenase the $(R)$-hydrogen atom is removed from the substrate and transferred to the pyridine nucleotide. The stereochemical course of the highly substrate specific plant alcohol dehydrogenase is therefore the same as that reported for horse liver and yeast alcohol dehydrogenase [5], in spite of the fact that the latter enzymes possess a completely different substrate specificity and differ completely in their taxonomic distribution.

Recently, using an approach via the labelled pyridine nucleotide, an identical stereochemical course for cinnamyl alcohol dehydrogenase from soybean cell suspension cultures was found [6]. From these results one can generalize that the majority of cinnamyl alcohol dehydrogenases which are involved in lignin formation in higher plants [3] transfer the A-hydrogen of NADPH [2] to the Re-site of coniferyl aldehyde. The complete sequence for the enzymic formation of lignin monomers, the cinnamyl alcohols, is depicted for the reduction of ferulic acid to coniferyl alcohol in Scheme 3. The stereochemical steps are also included. The differently labelled $\left(\gamma-{ }^{3} \mathrm{H}\right)$-coniferyl alcohols have also proved to be useful for autoradiographic studies currently in progress on lignin formation in differentiated tissue.

\section{EXPERIMENTAL}

All biochemicals were obtained from Boehringer, Mannheim. Preparation of coniferyl aldehyde. Commercially available coniferyl alcohol (Roth, Karlsruhe) was transformed into coniferyl aldehyde as follows: $30 \mu \mathrm{mol}$ coniferyl alcohol, $11.25 \mu \mathrm{mol}$ NAD. $0.4 \mathrm{mg}(1.08 \mathrm{U})$ horse liver $\mathrm{ADH}, 300 \mu \mathrm{mol}$ pyruvate, $0.2 \mathrm{mg}(110 \mathrm{U})$ lactate dehydrogenase, $100 \mu \mathrm{mol}$ glycine buffer (pH 8.7) were incubated at $30^{\circ}$ in a total vol. of $3 \mathrm{ml}$ and the reaction followed at $400 \mathrm{~nm}$ (absorption peak of the coniferyl aldehyde [2]). After $3 \mathrm{hr}$ the reaction was terminated and the incubation mixture extracted with ether $(4 \times 6 \mathrm{ml})$. The aldehyde was purified by TLC using Si gel and $\mathrm{CHCl}_{3} \mathrm{MeOH}$ $n$-hexane $(13: 2: 3)$. Under these conditions coniferyl alcohol had an $R_{f}$ of 0.56 while the aldehyde had $R_{f} 0.74$. The yield of the aldehyde was $89 \%$. The $\varepsilon_{400}$ of the aldehyde was determined at $20.38 \times 10^{6} \mathrm{~cm}^{2} / \mathrm{mol}$.

Preparation of $(\mathbf{R})-\left(\gamma^{3} H\right)$-coniferyl alcohol. $4.2 \mu \mathrm{mol}$ cyclohexanol (sp. act. $23.3 \mu \mathrm{Cl} / \mu \mathrm{mol}$ ), [5] was added to $4.2 \mu \mathrm{mol}$ coniferyl aldehyde, $0.5 \mu \mathrm{mol} \mathrm{NAD,} 0.4 \mathrm{mg}$ (1.08 U) ADH and $100 \mu \mathrm{mol}$ glycine buffer (pH 8.7). The mixture was incubated for $2 \mathrm{hr}$ under the conditions described above for the isolation of the aldehyde and the resulting labelled alcohol extensively purified. The yield of labelled alcohol was $7 \%$ with a $\mathrm{sp}$. act. of $21.5 \mu \mathrm{Ci} / \mu \mathrm{mol}$. The $\varepsilon_{280}$ of coniferyl alcohol was $7.74 \times 10^{6}$ $\mathrm{cm}^{2} / \mathrm{mol}$.
Preparation of (R,S)- $\left(\gamma-{ }^{3} \mathrm{H}\right)$-coniferyl alcohol. $27 \mu \mathrm{mol}$ coniferyl aldehyde was dissolved in $0.5 \mathrm{ml}$ triethyleneglycol dimethyl ether and this mixture added to an ampoule containing solid $\mathrm{NaBH}_{3} \mathrm{~T}(100 \mathrm{mCi} ; \mathrm{sp}$. act. $6 \mathrm{mCi} / \mu \mathrm{mol})$. After $3 \mathrm{hr}$ the mixture was subjected to TLC in the above solvent system and the resulting labelled coniferyl alcohol isolated with a yield of 25.5 $\mu \mathrm{mol}(94.4 \%)$.

Preparation of $\left(\gamma^{3} H\right)$-coniferyl aldehyde. $8.25 \mu \mathrm{mol}(R, S)$ $\left(\gamma-{ }^{3} \mathrm{H}\right)$-coniferyl alcohol $(3.24 \mu \mathrm{Ci} / \mu \mathrm{mol}), 7.5 \mu \mathrm{mol} \mathrm{NAD}, 0.4 \mathrm{mg}$ (1.08 U) ADH, $100 \mu \mathrm{mol}$ pyruvate, $0.2 \mathrm{mg}(110 \mathrm{U})$ lactate dehydrogenase and $100 \mu \mathrm{mol}$ glycine buffer ( $\mathrm{pH} 8.7$ ) were incubated. After $2.5 \mathrm{hr}$ the aldehyde formed was isolated as above and purified. The yield of aldehyde was $86 \%$, with a sp. act. of $1.45 \mu \mathrm{Ci} / \mu \mathrm{mol}(83 \%$ of the theoretical radiochemical yield).

Preparation of (S)- $\left(\gamma^{3} \mathrm{H}\right)$-coniferyl aldehyde. $7.09 \mu \mathrm{mol}\left(\gamma^{3} \mathrm{H}\right)$ coniferyl aldehyde $(7.44 \mu \mathrm{Ci})$ was added to a mixture of 15 $\mu \mathrm{mol}$ NADH, $0.4 \mathrm{mg}(1.08 \mathrm{U}) \mathrm{ADH}$ and $100 \mu \mathrm{mol}$ Tris-HCl buffer ( $\mathrm{pH} 7.7$ ). After $2 \mathrm{hr}$ incubation the alcohol formed was isolated and purified as above. The yield of stereospecifically tritiated alcohol was $60 \%$ with a sp. act. of $1.33 \mu \mathrm{Ci} / \mu \mathrm{mol}$ ( $92.7 \%$ of theoretical yield).

Enzyme assay. Cinnamyl alcohol dehydrogenase was isolated according to [2] from young lignifying stems of Forsythia suspensa grown in a phytotron. Preparations of both purified and crude enzymes gave essentially the same reaction stereochemistry. The same enzyme assay was used as above.

Acknowledgement-We thank the 'Deutsche Forschungsgemeinschaft' for financial support of this investigation.

\section{REFERENCES}

1. Gross, G. G. (1977) Rec. Adv. Phytochemistry (Loewus, F. A. and Runeckles, V. C. eds) Vol, 11, p. 141.

2. Mansell, R. L., Gross, G. G., Stöckigt, J., Franke, H. and Zenk, M. H. (1974) Phytochemistry 13, 2427.

3. Mansell, R. L., Babbel, G. R. and Zenk, M. H. (1976) Phytochemistry 15, 1849.

4. Wyrambik, D. and Grisebach, H. (1975) European J. Biochem. $59,9$.

5. Battersby, A. R., Staunton, J. and Whiltshire, H. R. (1975) J. Chem. Soc. Perkin I 1156.

6. Grisebach, H., Wengenmeyer, H. and Wyrambik, D. (1977) 2nd International Symposium on Pyridine Nucleotide Dependent Dehydrogenases, Konstanz (Germany) pp. 1-12.

7. Itokawa, H., Takeya, K. and Akasu, M. (1976) Chem. Pharm. Bull. 24, 1681.

Note added in proof - In a paper [7] which recently came to our attention, similar conclusions were reached concerning the stereochemical mechanism of the dehydrogenation reaction of a non-specific plant ADH with deuterium labelled cinnamyl alcohol. 